\title{
Creativity, birth order, and risk taking
}

\author{
RUSSELL EISENMAN \\ Temple University, Philadelphia, Pennsylvania
}

\begin{abstract}
Several hypotheses were formed and supported regarding the greater creativity and risk taking of firstborn males. It was also found, in this sample of 200 white middle-class adult males, that risk taking and creativity were related. The creativity measures included Eisenman's (1969) Personal Opinion Survey measure of creative attitudes, an unusual-uses test yielding scores for fluency and originality, and preference for complexity. All the predictions were significant beyond the .01 level. The greater risk taking of firstborn males found in the present study is somewhat incompatible with the results of previous birth-order/risk-taking research, and this discrepancy is discussed.
\end{abstract}

Several studies have shown a link between creativity and risk taking, with highly creative persons more willing to take risks than less creative subjects. Merrifield, Guilford, Christensen, and Frick (1961) found a significant relationship between associational fluency and a personality inventory measure of risk taking. Other investigators have been concerned with showing a relationship between risk taking and creativity in performance measures of risk taking. Pankove and Kogan (1968) utilized alternate uses and pattern meanings as creativity measures and compared performance on these tests to risk taking on a shuttleboard task; they found small but positive relationships. Eisenman (1969) measured creativity by scores on his Personal Opinion Survey, a 30-item, true-false, paper-and-pencil measure of creative attitudes; he found that creative college students so identified were more willing to risk their semester's grade on one test than were less creative students. Thus, all three investigations linked creativity and risk taking, with the subjects having been children or adults, and the tasks differing from study to study with regard to both creativity and risk taking. Also, these investigators controlled for intelligence or academic ability, so the results relate creativity to risk taking independent of the effects of intelligence. Creativity measures are usually considered to tap divergent thinking abilities, apart from the convergent thinking demanded by IQ and academic achievement tests.

The aim of the present study was to determine whether firstborn males would be more creative and more willing to engage in risk taking than later-born males. Birth order has many empirical correlates, presumably due to differential treatment by parents based on the child's ordinal position. Genetic factors could also relate to birthorder findings. Kagan (1969) noted that every child and adult lives in a social structure and has some awareness of his/her position in that structure. A disproportionate number of firstborns are named as Rhodes scholars, are listed in Who's Who, and achieve distinction in science

The author's address is: Department of Psychology (265-67), Temple University, Philadelphia, PA 19122.
(Kagan, 1969). Eisenman and Schussel (1970) showed that firstborn males scored higher than later-born males on several creativity tests. The present study focused on males, because there seems to be a relationship between creativity and being a firstborn male. It was expected that (1) there would be a positive relationship between creativity and risk taking, (2) firstborns would score higher than later-borns on the three creativity measures utilized in the present study, and (3) firstborns would score higher than later-borns on risk taking.

\section{METHOD}

\section{Subjects}

The subjects were 200 adult males, 100 firstborns and 100 later-borns, who were members of clubs and organizations in the greater Philadelphia area. All subjects were white and middle-class, and ranged in age from 27 to 59 .

\section{Measures}

Three creativity measures, one IQ measure, and a risk-taking measure were utilized. One creativity measure was the Personal Opinion Survey (Eisenman, 1969), which is a 30-item, true-false questionnaire measuring creative attitudes. The test seems to be reliable and valid (see Eisenman, 1970; also, the author has found that music students who won national awards for their music and were rated as creative by their instructors scored significantly higher on the questionnaire than music students who did not win awards and were not rated as creative).

The second creativity measure was an unusual-uses test, in which subjects were asked to give all the uses they could think of for a brick. This is a widely used creativity measure, and gives two scores: fluency, or the total number of uses given, and originality, or the unusualness of the uses given. Creativity seems to relate more to originality than to fluency, although the two could go hand in hand.

The third creativity measure was preference for complexity. Polygons varying in numbers of points were used, with greater numbers of points indicating greater complexity. This measure, preference for complexity over preference for simplicity, has been linked to creativity (Barron, 1963; Eisenman, 1968).

To control for intelligence, subjects were administered the vocabulary subtest of the Wechsler Adult Intelligence Scale (Wechsler, 1955). The risk-taking measure is described below.

\section{Procedure}

Subjects were tested in groups, with members of an organization tested together. An assistant passed out the test materials. Subjects filled out an information sheet that requested data on birth order, family size, and 
other demographic variables. The order of administration of the creativity measures and the IQ subtest was randomly varied. The assistant read the vocabulary words aloud to the subjects, who wrote the words' meaning on their papers. The risk-taking measure was always the last thing the subjects dealt with. They were told they could participate in one of two experiments, involving a chance to win a little or a lot of money. In the experiment in which a little money could be won, they were told, there were no negative consequences associated with not winning money; however, in the experiment in which a lot of money could be won, painful but not harmful electric shocks would be given to those who did not win. Subjects had to choose one of these experiments; the "lot of money/shock" experiment was defined as the high-risk option. No subject dropped out of the study at any point. After the data had been gathered from all subjects, they were told that there really was no experiment involving money or shock, and the research was explained to them. The size of the groups ranged from 20 to 42 people, and the club officers always helped in running the subjects and legitimating the procedures.

\section{RESULTS}

A score of 1 was assigned to the low-risk option and a score of 2 was assigned to the high-risk (money/shock) option. Risk taking correlated significantly with all three creativity measures: .37 with the Personal Opinion Survey measure of creative attitudes, .34 with unusual-uses originality scores, and .35 with preference for complexity. All $r$ s were significant beyond the .01 level. The correlation of risk taking with unusual-uses fluency was $.34(p<.01)$; the risk taking and IQ (vocabulary subtest) $r$ of .09 was not significant.

To relate birth order to creativity scores, $2 \times 2$ chisquare analyses were performed, utilizing normative data obtained from students at Temple University. Subjects were classified as above or below the median creativity scores for Temple students for each of the measures utilized. On the Personal Opinion Survey, 67 of the 100 firstborns scored above the college median, whereas only 45 of the 100 later-borns did so $\left[\chi^{2}(1)=9.82, p<.01\right]$. For both unusual-uses fluency and originality, 55 of the 100 firstborns scored above the college median, whereas only 37 of the 100 later-borns did so $\left[\chi^{2}(1)=6.52\right.$, $p<.01]$. For preference for complexity, only 34 out of 100 firstborns scored above the college median, whereas only 20 of the 100 later-born subjects did so $\left[x^{2}(1)=4.97, p<.01\right]$. There was no significant difference between firstborns and later-borns on IQ (vocabulary) scores $[t(198)=1.20, p>.10]$.

The high-risk option was chosen by 48 of the 100 firstborns, compared to only 27 of the 100 later-borns $\left[\chi^{2}(1)=9.42, p<.01\right]$. Attempts to relate the findings to age, family size, or IQ (vocabulary) by chi-square and correlation measures proved statistically nonsignificant.

\section{DISCUSSION}

The results are consistent with the hypotheses about the relationship between risk taking and creativity, between creativity and being a firstborn male, and between risk taking and being a firstborn male. The last finding is perhaps the most surprising. Many previous studies could have led to the opposite prediction, that is, that firstborns would be less likely than later-borns to take risks. There has been emphasis in the past on the firstborn's greater anxiety and fear of physical injury (Helmreich \& Collins, 1967; Nisbett, 1968; Nisbett \& Schachter, 1966). Also, conservatism in firstborns would follow from Adler's theory about birth order (Ansbacher \& Ansbacher, 1959). It may be that in many situations firstborns do strive to avoid harm. In the present study, however, the focus may have been more on acquiring money than on the fear of electric shock. The subjects needed only confidence in their ability to succeed to believe they would get the money and avoid the electric shock.

The results are consistent with the expectation of greater creativity in firstborn males than in later-born males. Perhaps the greater achievement orientation and greater time alone with adults (before the birth of a sibling) leads to greater likelihood of creativity by allowing a person to think deeply and differently about things most taken for granted. It is interesting that these adult subjects preferred less complexity than the Temple University students. Perhaps age or life-style differences accounted for this finding. Because only nine polygons were used, varying in number of points from 4 to 24 (see Eisenman, 1968, for more details), the range of complexity present might have made a difference. It is also interesting that fluency was as good a score as originality in the present study. Because subjects tend to give original uses for the brick toward the end of their responding, the fluent person has a greater opportunity to be original. That is, the early responses tend to be mundane, and only after these are exhausted do many subjects start to report original uses.

\section{REFERENCES}

ANSBACHER, H. L., \& ANSBACHER, R. R. (Eds.). (1959). The Individual Psychology of Alfred Adler. New York: Basic Books.

BARron, F. (1963). Creativity and psychological health. Princeton, NJ: Van Nostrand.

Eisenman, R. (1968). Personality and demography in complexitysimplicity. Journal of Consulting \& Clinical Psychology, 32, 140-143.

EISENMAN, R. (1969). Components of creativity, verbal conditioning, and risk taking. Perceptual \& Motor Skills, 29, 687-700.

Eisenman, R. (1970). Creativity change in student nurses: A crosssectional and longitudinal study. Developmental Psychology, 3, 320-325.

EISENMAN, R., \& SChussel, N. R. (1970). Creativity, birth order, and preference for symmetry. Journal of Consulting \& Clinical Psychology, 34, 275-280.

HelmReich, R. L., Collins, B. E. (1967). Situational determinants of affiliative preferences under stress. Journal of Personality \& Social Psychology, 6, 79-85.

KagAN, J. (1969). Peer and sibling influences. In I. L. Janis, G. F. Mahl, J. Kagan, \& R. R. Holt (Eds.), Personality (pp. 541-555). New York: Harcourt, Brace \& World.

Merrifield, P. R., Guilford, J. P., Christensen, P. R., \& Frick, J. W. (1961). Interrelationships between certain abilities and certain traits of motivation and temperament. Journal of General Psychology, 65, 57-74.

NisBeTT, R. E. (1968). Birth order and participation in dangerous sports. Journal of Personality and Social Psychology, 8, 351-353.

NisbetT, R. E., \& SCHAChTER, S. S. (1966). Cognitive manipulation of pain. Journal of Experimental Social Psychology, 2, 227-236.

Pankove, E., \& Kogan, N. (1968). Creative ability and risk taking in elementary school children. Journal of Personality, 36, 420-439. WECHSLER, D. (1955). Wechsler Adult Intelligence Scale: Manual. New York: Psychological Corporation.

(Manuscript received for publication September 29, 1986.) 